\title{
Peranan Pengetahuan Pajak dan Kesadaran Pajak bagi Kepatuhan Pajak Pelaku Usaha E-Commerce
}

\author{
Olivia Afrinadea Chanita, Norman Duma Sitinjak* \\ Fakultas Ekonomi dan Bisnis Universitas Merdeka Malang, Malang, Indonesia \\ *norman.duma@unmer.ac.id
}

\begin{abstract}
Research to examine the role of tax knowledge and tax awareness for tax compliance by e-commerce entrepreneurs. The sample is 50 e-commerce entrepreneurs, obtained by a simple random sample technique. Multiple linear regression was used to analyze the effect of tax knowledge and awareness on tax compliance. The important point of the research results is that knowledge and awareness of taxes owned by e-commerce entrepreneurs have a positive effect on tax compliance.
\end{abstract}

Keywords: E-Commerce Entrepreneur, Tax Awareness, Tax Compliance, Tax Knowledge

\section{PENDAHULUAN}

Pemanfaatan teknologi berbasis digital semakin marak di Indonesia. Seperti yang diungkap oleh Riyanto (2020) tentang Indonesian Digital Report bahwa per Januari 2020 dari 272,1 juta penduduk di Indonesia ada 160 juta orang aktif menggunakan media sosial.

Penggunaan media sosial memberikan perubahan pada perdagangan di Indonesia. Proses perdagangan yang disebut dengan $e$ commerce bertambah marak. Di Indonesia pertumbuhan e-commerce setiap tahun terus meningkat. Kemkominfo (2019) menjelaskan bahwa pertumbuhan $e$ commerce di Indonesia pada tahun 2019 tertinggi di dunia yaitu sebesar $78 \%$. Cahya (2020) menyampaikan bahwa sejak awal pandemi Covid 19 jumlah pelanggan $e$ commerce meningkat pesat, terutama karena ada Pembatasan Sosial Berskala Besar (PSBB). Perdagangan secara online sangat diminati masyarakat disebabkan pembeli dengan hanya di rumah memiliki kesempatan untuk melihat dan memilih produk yang diinginkan.bagi penjual, mereka juga tidak harus memiliki toko secara fisik untuk tempat jualan.

Penerimaan terbesar Indonesia berasal dari pajak. Andry (2021) menyampaikan bahwa besaran kontribusi pajak bagi penerimaan negara sebesar Rp. $1.865,7$ triliun atau 83,54\%. Angka sebesar 83,54\% pada satu sisi menunjukkan sumbangsih pajak yang semakin besar, namun pada sisi yang berbeda menunjukkan ketergantungan atas pajak. Pemerintah harus meningkatkan perhatian pada pajak. Peningkatan transaksi e-commerce menjadi salah satu faktor untuk optimalisasi peneriman pajak.

Pemerintah menerbitkan PP Nomor 23 Tahun 2018 untuk meningkatkan penerimaan pajak termasuk dari pelaku usaha $e$ commerce Peraturan pajak yang dikenakan kepada pelaku usaha yang penghasilan bruto setahun tidak melebihi Rp. 4,8 Miliar. PP Nomor 23 Tahun 2018 umum disebut sebagai peraturan pajak UMKM. Tarif yang dikenakan yaitu $0,5 \%$ atas omzet, sejauh penjualan kotor dalam satu tahun tidak lebih besar dari Rp. 4,8 Miliar. Berdasarkan PP Nomor 23 Tahun 2018 pelaku usaha tidak 
akan mengalami kesulitan dalam menghitung pajak, karena hanya dengan menjumlah semua penjualan bruto dikalikan dengan tarif sebesar $0,5 \%$. Pembayaran dan pelaporan pajak dilakukan dengan mudah. Pembayaran dapat menggunakan e-billing dan pelaporan menggunakan $e$-filing. Bagi pelaku usaha $e$ commerce tidak mengalami kesulitan dalam mempelajari penggunaan e-billing dan $e$ filing karena semua petunjuk penggunaan ada di media internet. Media yang familiar bagi pelaku usaha e-commerce.

Pajak merupakan sejumlah dana yang wajib dibayar ke negara, bersifat memaksa dan yang melanggar dikenai sanksi. Namun demikian banyak pengusaha termasuk UMKM belum patuh atas pajak. Pebrianto (2020) menjelaskan bahwa pada tahun 2019 masih sebagian kecil pelaku UMKM di Indonesia yang membayar pajak. Dari total 60 juta UMKM baru 2 juta yang membayar pajak.

Kepatuhan atas penerapan perpajakan dipengaruhi beberapa hal, diantaranya adalah pengetahuan pajak dan kesadaran pajak. Oladipupo dan Obazee (2016), Samadiartha dan Darma (2017), dan Yoeanda et al. (2018) menjelaskan bahwa pengetahuan Wajib Pajak (WP) tentang perpajakan berperan dalam meningkatkan kepatuhan pajak. Pengetahuan tentang pajak yang semakin baik membuat WP semakin memahami prosedur tentang pajak sehingga mampu menjalani kewajiban pajak. Ningsih et al. (2019) serta Andreas dan Savitri (2015) menjelaskan bahwa kesadaran atas pajak mendorong WP untuk semakin mematuhi pajak.

Penelitian terdahulu yang menguji dampak pengetahuan perpajakan dan kesadaran atas kepatuhan peraturan telah banyak dilakukan. Penelitian Oladipupo dan Obazee (2016) dan Yoeanda et al. (2018) hasilnya menjelaskan bahwa pengetahuan pajak berpengaruh atas praktik kepatuhan perpajakan e-commerce, sedangkan (Arisandy, 2017) dan Ningsih et al. (2019) menjelaskan bahwa pengetahuan pajak tidak berpengaruh atas praktik kepatuhan perpajakan e-commerce. Penelitian Ningsih et al. (2019) dan Andreas dan Savitri (2015) menjelaskan kesadaran pajak mendorong kepatuhan pajak.

Penelitian ini kembali menguji peranan pengetahuan perpajakan terhadap kepatuhan perpajakan UMKM e-commerce. Alasan pertama adalah adanya perbedaan hasil penelitian mengenai peranan pengetahuan perpajakan terhadap kepatuhan perpajakan. Alasan kedua adalah penelitian ini dilakukan tahun 2021, dimana sejak bulan Maret 2020 Indonesia mengalami pandemi Covid 19, selain itu perhatian pemerintah terhadap pajak dari usaha e-commerce setiap tahun semakin meningkat.

Perhatian tersebut misalnya pada tahun 2018 pemerintah menerbitkan PP Nomor 23 Tahun 2018 sebagai upaya membantu pelaku usaha e-commerce agar lebih ringan dan patuh pajak. Variabel kesadaran pajak disertakan dalam penelitian ini untuk mengetahui konsistensi peranan kesadaran perpajakan terhadap kepatuhan pajak pada masa pandemi. Penerapan PP Nomor 23 Tahun 2018 masih dapat dikatakan baru lahir, sehingga perlu dikaji. Peraturan ini khusus berlaku untuk pengusaha yang penjualan kotor setahun tidak lebih besar dari Rp4,8 M. Pelaku usaha online banyak yang termasuk kelompok UMKM.

Tujuan kajian ini adalah menguji kembali peranan pengetahuan dan kesadaran pajak terhadap kepatuhan pajak karena masih ada perbedaan pada hasil penelitian sebelumnya untuk hasil penelitian pengetahuan perpajakan bagi kepatuhan perpajakan dan adanya pandemic Covid 19 di Indonesia sejak maret 2020.

\section{E-Commerce}

Laudon dan Laudon (2010) menjelaskan e-commerce merupakan proses perdagangan dengan media elektronik sebagai media bertransaksi. Pembeli dan penjual tidak harus bertemu seperti perdagangan konvensional. Pemilihan pelaku UMKM e-commerce sebagai objek penelitian karena menurut Kemkominfo (2019) pertumbuhan $e$-commerce tertinggi di dunia tahun 2019 ada di Indonesia. 


\section{Pengaruh Pengetahuan atas Pajak Terhadap Kepatuhan Pajak}

Pengetahuan pajak dijelaskan oleh Palil et al. (2013) sebagai pemahaman WP mengenai peraturan pajak yang terkait dengan aktivitas atau kegiatan. Semakin baik pengetahuan pajak maka kemampuan dalam memahami peraturan termasuk menghitung, membayar dan melapor pajak juga semakin baik, sehingga pengetahuan pajak membantu seseorang saat memenuhi kewajiban pajak.

Pengetahuan pajak bermanfaat bagi kepatuhan pajak dibuktikan oleh Oladipupo dan Obazee (2016) serta Yoeanda et al. (2018) yaitu pengetahuan pajak yang semakin tinggi akan membantu seseorang atau WP untuk mematuhi peraturan pajak.

$\mathrm{H}_{1}$ : Pengetahuan pajak memberikan pengaruh positif bagi kepatuhan pajak

\section{Pengaruh Kesadaran Pajak bagi Kepatuhan Pajak}

Kesadaran pajak dijelaskan oleh Harahap (2004) sebagai sikap WP atas sumber dan manfaat pajak. WP yang memahami bahwa pajak bersumber dari masyarakat dan digunakan pemerintah bagi kesejahteraan masyarakat akan memiliki kerelaan dalam mematuhi pajak.

Peranan kesadaran pajak terhadap kepatuhan pajak dibuktikan oleh Ningsih et al. (2019) serta Andreas dan Savitri (2015) bahwa kesadaran pajak yang semakin tinggi mampu mendorong kepatuhan perpajakan.

$\mathrm{H}_{2}$ : Kesadaran pajak memberikan pengaruh positif bagi kepatuhan pajak

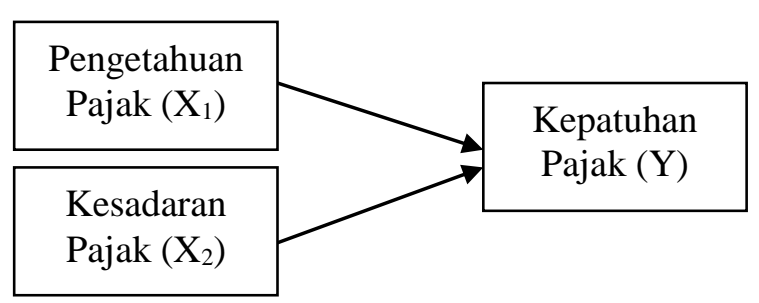

Gambar 1. Kerangka Penelitian

\section{METODE}

Metode penelitian yang dipakai ialah kuantitatif. Sumber data adalah primer. Data didapat dengan menyebarkan kuesioner menggunakan google form. Teknik sampling yang digunakan simple random, karena sampel diambil secara acak. Semua sampel adalah pelaku usaha e-commerce yang omzetnya dalam setahun tidak melebihi Rp4,8 M, sesuai dengan kriteria pelaku usaha UMKM menurut aturan pajak yang tertuang di PP Nomor 23 Tahun 2018.

Jumlah sampel menggunakan patokan yang disampaikan oleh Roscoe (1982), yaitu penelitian dengan multivariate analysis maka jumlah sampel setidaknya 10 kali dari jumlah variabel penelitian. Variabel penelitian ada 3, sehingga minimal sampel adalah 30. Jumlah Sampel digunakan sebanyak 50 online shop.

Tabel 1. Karakteristik Sampel Berdasarkan Pendidikan

\begin{tabular}{|c|c|c|c|}
\hline No & Pendidikan & $\begin{array}{l}\text { Jumlah } \\
\text { Sampel }\end{array}$ & $\%$ \\
\hline 1. & SMP & 1 & 2 \\
\hline 2. & SMA & 28 & 56 \\
\hline 3. & Diploma (D1 / D2 / D3) & 1 & 2 \\
\hline 4. & $\mathrm{~S} 1$ & 20 & 40 \\
\hline \multicolumn{2}{|c|}{ Jumlah } & 50 & 100 \\
\hline
\end{tabular}

Berdasarkan Tabel 1 dapat didjelaskan bahwa 96\% tingkat pendidikan responden adalah SMA sampai sarjana.

Tabel 2. Karakteristik Sampel Berdasarkan Omzet

\begin{tabular}{lccr}
\hline No & Omzet & $\begin{array}{c}\text { Jumlah } \\
\text { Sampel }\end{array}$ & $\%$ \\
\hline 1. $\quad<$ 300 Juta & 48 & 96 \\
2. 300 Juta - 1 Miliar & 2 & 4 \\
Jumlah & 50 & 100 \\
\hline
\end{tabular}

Berdasarkan Tabel 2 diketahui bahwa semua responden adalah pelaku usaha dengan klasifikasi UMKM. Sesuai dengan kriteria UMKM menurut pajak dalam PP Nomor 23 Tahun 2018. 
Validitas Dan Reliabilitas

Tabel 3. Hasil Uji Validitas

\begin{tabular}{|c|c|c|c|c|}
\hline Variabel & Item & $\begin{array}{c}\text { Nilai } \\
\text { Korelasi }\end{array}$ & $\begin{array}{c}\mathrm{r} \text { tabel }(\mathrm{N} \\
=50 ; \alpha \\
=5 \%)\end{array}$ & Ket. \\
\hline \multirow{10}{*}{$\begin{array}{l}\text { Kepatuhan } \\
\text { Wajib Pajak } \\
\text { (Y) }\end{array}$} & $\mathrm{y} 1$ & 0,575 & 0,279 & valid \\
\hline & $\mathrm{y} 2$ & 0,528 & 0,279 & valid \\
\hline & y3 & 0,557 & 0,279 & valid \\
\hline & y4 & 0,662 & 0,279 & valid \\
\hline & y5 & 0,689 & 0,279 & valid \\
\hline & y6 & 0,715 & 0,279 & valid \\
\hline & y7 & 0,659 & 0,279 & valid \\
\hline & y8 & 0,684 & 0,279 & valid \\
\hline & y9 & 0,618 & 0,279 & valid \\
\hline & $\mathrm{y} 10$ & 0,457 & 0,279 & valid \\
\hline \multirow{7}{*}{$\begin{array}{l}\text { Pengetahuan } \\
\text { Perpajakan } \\
\text { (X1) }\end{array}$} & $\mathrm{x} 1.1$ & 0,743 & 0,279 & valid \\
\hline & $\mathrm{x} 1.2$ & 0,724 & 0,279 & valid \\
\hline & $\mathrm{x} 1.3$ & 0,605 & 0,279 & valid \\
\hline & $\mathrm{x} 1.4$ & 0,507 & 0,279 & valid \\
\hline & $\mathrm{x} 1.5$ & 0,528 & 0,279 & valid \\
\hline & x1.6 & 0,531 & 0,279 & valid \\
\hline & x1.7 & 0,614 & 0,279 & valid \\
\hline \multirow{6}{*}{$\begin{array}{l}\text { Kesadaran } \\
\text { Wajib Pajak } \\
\text { (X2) }\end{array}$} & $\mathrm{x} 2.1$ & 0,596 & 0,279 & valid \\
\hline & $\mathrm{x} 2.2$ & 0,726 & 0,279 & valid \\
\hline & $\mathrm{x} 2.3$ & 0,714 & 0,279 & valid \\
\hline & $\mathrm{x} 2.4$ & 0,616 & 0,279 & valid \\
\hline & $\mathrm{x} 2.5$ & 0,710 & 0,279 & valid \\
\hline & x2.6 & 0,831 & 0,279 & valid \\
\hline
\end{tabular}

Berdasarkan Tabel 3 dapat dijelaskan seluruh item dapat digunakan sebagai alat pengumpulan data karena valid. Sedangkan berdasarkan Tabel 4 dapat dijelaskan seluruh butir kuesioner dapat digunakan sebagai alat pengumpul data karena reliable.

\section{Analisis Statistik Deskriptif}

Tabel 4. Analisis Deskriptif

\begin{tabular}{|c|c|c|c|c|c|}
\hline Keterangan & $\mathrm{N}$ & Minimum & Max & Mean & $\begin{array}{l}\text { Std. } \\
\text { Dev }\end{array}$ \\
\hline $\begin{array}{l}\text { Kepatuhan Wajib } \\
\text { Pajak (Y) }\end{array}$ & 50 & 25 & 50 & 39,08 & 5,57 \\
\hline $\begin{array}{l}\text { Pengetahuan } \\
\text { Perpajakan (X1) }\end{array}$ & 50 & 17 & 35 & 26,06 & 4,24 \\
\hline $\begin{array}{l}\text { Kesadaran Wajib } \\
\text { Pajak (X2) }\end{array}$ & 50 & 17 & 30 & 24,32 & 3,27 \\
\hline Valid N (listwise) & 50 & & & & \\
\hline
\end{tabular}

Berdasarkan Tabel 5 dijelaskan ratarata dari kepatuhan pajak, pengetahuan pajak dan kesadaran pajak mendekati nilai maksimal. Berarti kepatuhan pajak, pengetahuan pajak dan kesadaran pajak pelaku usaha berbasis e-commerce adalah baik.

\section{Asumsi Klasik}

Uji normalitas dilakukan dengan test of normality kolmogorov-smirnov. Hasil uji diketahui bahwa data terdistribusi dengan normal. Multikolinieritas diuji dengan VIF (Variance Inflation Factor). Hasil uji adalah tidak ada multikolinieritas pada model. Pengujian heteroskedastisitas dilakukan dengan Uji Glejser. Hasilnya adalah tidak terjadi heteroskedastisitas pada model.

\section{Uji Pengaruh}

Tabel 5. Hasil Uji Normalitas

\begin{tabular}{lccc}
\hline \multicolumn{1}{c}{ Variabel } & K-S & Sig. & Kep. \\
\hline Kepatuhan Wajib Pajak & 0,071 & 0,2 & Normal \\
Pengetahuan Perpajakan & 0,101 & 0,2 & Normal \\
Kesadaran Wajib Pajak & 0,097 & 0,2 & Normal \\
\hline
\end{tabular}

Berdasarkan Tabel 6 dapat dijelaskan bahwa bagi pelaku usaha atau pengusaha UMKM e-commerce, peningkatan pengetahuan perpajakan mampu meningkatkan kepatuhan perpajakan. Hasil penelitian sejalan dengan penelitian yang telah dilakukan sebelumnya (Oladipupo \& Obazee, 2016; Palil et al., 2013; Samadiartha \& Darma, 2017; Yoeanda et al., 2018).

Kesadaran pajak pelaku usaha atau pengusaha UMKM e-commerce juga mampu meningkatkan kepatuhan perpajakan. Hasil penelitian sejalan dengan Ningsih et al. (2019) serta Andreas dan Savitri (2015).

Peningkatan pengetahuan pajak mampu meningkatkan kepatuhan pajak menunjukkan jika semakin baik pengetahuan pajak pelaku usaha e-commerce maka kepatuhan pajak semakin baik juga. Pengetahuan pajak yang semakin baik menjelaskan bahwa pelaku usaha semakin memahami peraturan pajak yang terkait 
usaha yang dijalankan, yaitu berdagang melalui e-commerce.

Pengetahuan pajak dari pelaku usaha $e$ commerce yang menjadi sampel dalam penelitian adalah baik karena memahami bahwa harus memiliki NPWP, mengetahui batas akhir pembayaran dan pelaporan pajak, mengetahui cara menghitung pajak, dan mengetahui adanya sanksi perpajakan. Pengetahuan pajak yang baik akan mengingatkan pelaku usaha tentang apa yang harus dilakukan terkait kewajiban pajak. Tidak sulit untuk mengetahui peraturan pajak termasuk untuk UMKM, terutama yang biasa bekerja dengan media online. Pemerintah telah membagi semua informasi pajak di media online.

Bagi pelaku usaha e-commerce, dari semua peraturan yang menyebabkan peningkatan kepatuhan adalah keberadaan sanksi pajak. Sejalan dengan penelitian Tiraada (2013) bahwa sanksi pajak memiliki pengaruh paling besar dibandingkan bagian peraturan pajak yang lain bagi kepatuhan pajak. Sanksi pajak dikenakan bagi pelanggar. Sanksi dapat berupa administratif dan pidana. Pelaku usaha e-commerce dapat membayar dan melapor pajak dengan mudah karena dapat memanfaatkan $e$-billing dan $e$ filing serta perhitungan pajak untuk UMKM e-commerce sangat mudah. Tinggal menjumlahkan penerimaan bruto dan mengalikan dengan tarif pajak $0,5 \%$.

Kesadaran pajak dari pelaku usaha atau pengusaha UMKM e-commerce mampu meningkatkan kesadaran pajak. Kesadaran pajak dalam hal ini adalah terkait manfaat atau penggunaan pajak. pelaku usaha $e$ commerce menyadari bahwa pajak adalah sumber penerimaan terbesar pemerintah. Jika terjadi permasalahan yang menyebabkan penerimaan pajak menurun maka menyebabkan penurunan penerimaan pemerintah.

Pelaku usaha e-commerce menyadari bahwa penerimaan dari pajak dipakai dalam pembiayaan operasional pemerintah untuk melayani masyarakat, termasuk untuk meningkatkan kesejahteraan masyarakat. Penurunan penerimaan negara menyebabkan kegiatan pemerintah dalam melayani masyarakat dan upaya peningkatan kesejahteraan masyarakat juga dapat menurun. Dapat dikatakan jika masyarakat enggan mematuhi perpajakan maka akan menjadi bumerang bagi masyarakat sendiri. Dapat dibayangkan jika rasa aman dan nyaman yang dirasakan masyarakat berkurang akan sangat mengganggu dalam kegiatan sehari-hari.

Merujuk Tabel 6 dapat dijelaskan bahwa kesadaran pajak berperan lebih besar dibanding pengetahuan pajak dalam memberikan pengaruh terhadap kepatuhan pajak. Hal ini menunjukkan bahwa pengetahuan pajak dapat membuat seseorang taat terhadap pajak, namun kesadaran pajak menjadi dorongan utama bagi pelaku usaha e-commerce untuk mematuhi pajak, seperti yang dibuktikan oleh (Ningsih et al., 2019).

Kesadaran merupakan reaksi, jadi kesadaran pajak merupakan reaksi atas perpajakan di Indonesia. Pelaku usaha $e$ commerce merasa mematuhi peraturan pajak adalah suatu kewajaran, yang tidak wajar adalah mereka yang tidak patuh terhadap pajak.

\section{Kesimpulan}

Pengetahuan pajak yang semakin baik menyebabkan kepatuhan pajak meningkat. Pengetahuan pajak yang semakin baik membuat Pelaku usaha e-commerce paham kewajiban yang harus dilakukan terkait perpajakan.

Kesadaran pajak yang semakin baik mendorong peningkatan kepatuhan pajak. kesadaran pajak merupakan dorongan kesadaran akan menfaat dari dana pajak, sehingga membuat kepatuhan pajak semakin lebih baik.

\section{DAFTAR PUSTAKA}

Andreas, A., \& Savitri, E. (2015). The Effect of Tax Socialization, Tax Knowledge, Expediency of Tax ID Number and Service Quality on Taxpayers Compliance with Taxpayers Awareness as Mediating Variables. Procedia Social and Behavioral Sciences, 211, 
$163-169$.

https://doi.org/10.1016/j.sbspro.2015.11 .024

Andry. (2021). Pengaruh pengunduran pelaporan pajak terhadap APBN, serta Fungsi Pajak dalam mendukung APBN. Retrieved from www.pajakku.com website:

https://www.pajakku.com/read/5ea0faac 20249840da3c22ba/Pengaruh-

pengunduran-pelaporan-pajak-terhadapAPBN-serta-Fungsi-Pajak-dalammendukung-APBN

Arisandy, N. (2017). Pengaruh Pemahaman Wajib Pajak, Kesadaran Wajib Pajak dan Sanksi Pajak Terhadap Kepatuhan Wajib Pajak Orang Pribadi yang Melakukan Kegiatan Bisnis Online Di Pekanbaru. Jurnal Ilmiah Ekonomi Dan Bisnis, 14(1), 62-71.

Cahya, I. (2020). Pelanggan E-Commerce Naik 38,3 Persen Selama Pandemi. Retrieved from merdeka.com website: https://www.merdeka.com/teknologi/pel anggan-e-commerce-naik-383-persenselama-pandemi.html

Harahap, A. A. (2004). Paradigma baru perpajakan Indonesia: perspektif ekonomi-politik. Jakarta: Integrita Dinamika Press.

Kemkominfo. (2019). Kemkominfo: Pertumbuhan e-Commerce Indonesia Capai 78 Persen. Retrieved from Kementerian Komunikasi dan Informatika Republik Indonesia website: https://kominfo.go.id/content/detail/167 70/kemkominfo-pertumbuhan-ecommerce-indonesiacapai-78persen/0/sorotan_media

Laudon, K. C., \& Laudon, J. P. (2010). Essentials of Business Information Systems. Pearson Education.

Ningsih, A. S., Maslichah, \& Mawardi, M. C. (2019). Pengaruh Pemahaman Peraturan Pajak, Tarif Pajak, Lingkungan dan Kesadaran Wajib Pajak Terhadap Kepatuhan Wajib Pajak Pengguna E-Commerce. Jurnal Ilmiah Riset Akuntansi, 8(1), 82-91.
Oladipupo, A., \& Obazee, U. (2016). Tax Knowledge, Penalties and Tax Compliance in Small and Medium Scale Enterprises in Nigeria. iBusiness, 08, 19.

https://doi.org/10.4236/ib.2016.81001

Palil, M. R., Akir, M. R. M., \& Ahmad, W. F. B. W. (2013). The perception of tax payers on tax knowledge and tax education with level of tax compliance: A study the influences of religiosity. ASEAN Journal of Economics, Management and Accounting, 1(1), 118-129.

Pebrianto, F. (2020). 58 Juta Pelaku UMKM Belum Bayar Pajak. Retrieved from https://bisnis.tempo.co/ website: https://bisnis.tempo.co/read/1309087/58 -juta-pelaku-umkm-belum-bayar-pajak

Riyanto, A. D. (2020). Hootsuite (We are Social): Indonesian Digital Report 2020. Retrieved from hootsuite website: https://andi.link/hootsuite-we-aresocial-indonesian-digital-report-2020/

Roscoe. (1982). Research Methods for Business. New York: Mc Graw Hill.

Samadiartha, I. N. D., \& Darma, G. S. (2017). Dampak Sistem E-Filing, Pengetahuan Perpajakan, Sosialisasi Perpajakan, Kesadaran Wajib Pajak terhadap Kepatuhan Wajib Pajak. Jurnal Manajemen Bisnis, 14(1), 75103.

Tiraada, T. A. M. (2013). Kesadaran Perpajakan, Sanksi Pajak, Sikap Fiskus Terhadap Kepatuhan WPOP Di Kabupaten Minahasa Selatan. JURNAL EMBA: Jurnal Riset Ekonomi, Manajemen, Bisnis Dan Akuntansi, 1(3), 999-1008.

Yoeanda, Q., Afifudin, \& Mawardi, M. C. (2018). Faktor-Faktor Yang Mempengaruhi Tingkat Kepatuhan Wajib Pajak (Studi Kasus Wajib Pajak OP Pelaku e-commerce di Kota Malang). Jurnal Ilmiah Riset Akuntansi, 7(8), 52-64. 